\title{
Technical Efficiency in Public Hospitals in Kenya: A Two -Stage Data Envelopment Analysis
}

\author{
Francis Kimani Mwihia ${ }^{1}$, James Machoki M' Imunya ${ }^{1}$, Germano Mwabu ${ }^{2}$, \\ Urbanus M. Kioko ${ }^{2} \&$ Benson B. A. Estambale ${ }^{1,3}$ \\ ${ }^{1}$ Institute of Tropical and Infectious Diseases, University of Nairobi, Kenya \\ ${ }^{2}$ School of Economics, University of Nairobi, Kenya \\ ${ }^{3}$ Jaramogi Oginga Odinga University of Science and Technology, Kenya \\ Correspondence: Kimani Francis Mwihia, University of Nairobi Institute of Tropical and Infectious Diseases \\ (UNITID), P.O. Box 30197- 00100 GPO Nairobi, Kenya. E-mail: drfranciskimani@ gmail.com
}

Received: April 11, 2018

doi:10.5539/ijef.v10n6p141
Accepted: May 3, 2018

Online Published: May 10, 2018

URL: https://doi.org/10.5539/ijef.v10n6p141

\begin{abstract}
The paper uses the DEA technique to estimate efficiency scores in Kenyan public hospitals and then applies the Tobit regression to study inter-hospital variation in the scores. The DEA analysis reveals that small hospitals are more efficient than large hospitals, with efficiency levels ranging from 74-91\% in small DMUs and from 57-78\% in large DMUs. Tobit regression analysis shows efficiency scores are negatively correlated with the hospital's distance from the manager's residence and from the capital city. Internal and external supervisions are suggested as mechanisms for increasing performance of hospitals.
\end{abstract}

Keywords: hospitals, technical and scale efficiency, DEA, Tobit regression, hospital supervision, Kenya

\section{Introduction}

Hospitals are established to restore health to those inflicted by diseases and infirmity and to sustain good health through preventive measures. To a certain extent, people's health depends on how well the health system functions and the way the health system works is determined by the efficiency of hospitals in performing their functions (Nazagul, 2011). Health care systems in many developing countries especially in Sub-Saharan Africa have a shortage of healthcare resources that are attributed to poor economic performance, rapid population growth, and a decline in public spending. Additionally, communicable, maternal, nutritional, and new borne diseases continue to dominate and putting stress on the already scarce health care resources of these countries (Ali et al., 2017). In sub-Saharan Africa, hospitals absorb the greatest proportion of the total health expenditure, which is estimated at $45-69 \%$ of the public health budget. Thus there is a need to bring into sharp focus hospital management issues in order to generate additional resources for the health system through efficiency savings (Mills et al., 1991; Kirigia et al., 1998). Efficiency in health care is achieved when a maximum quantity of service has been produced with a given resource amount or when a given level of service has been produced at least cost (Molem \& Beri, 2016; Moshiri et al., 2011). Data Envelopment Analysis (DEA) method is the tool commonly used to measure technical efficiency of private and public organizations, known in the efficiency analysis literature as decision-making units (DMUs) (Charnes, Cooper, \& Rhodes, 1978).

The concept of modern efficiency began with Farrell (1957) who drew upon the work of Debreu 1951 and Koopmans 1951 to define a simple measure of firm efficiency which could account for multiple inputs. He proposed that the efficiency of a firm consists of two components; Technical efficiency which reflects the ability of a firm to obtain maximal output from a given set of inputs and a locative efficiency, which reflects the ability of a firm to use the inputs in optimal proportions, given their respective prices. These two are then combined to provide a measure of total economic efficiency. Technical efficiency measures the usage of labor, capital, and machinery as input to produce outputs relative to best practice in a given sample of DMUs i.e. given the same technology for DMUs. No wastage of inputs considered in producing the quantity of output. An organization operating at best practice in comparison to all others in the sample is said to be totally technically efficient.

Jehu-Appiah et al. (2014) state that seeking to attain efficiency have become the central objective of policy-makers within most health systems. This is much more evident in Africa where the ability to adequately 
meet health care needs is made worse by extensive inefficiencies, especially within the hospital sector. Kirigia and Asbu (2013) state that it is generally accepted that improved efficiency is one of the four overarching goals of health systems. According to Moshiri et al. (2010) measurement of efficiency is the first step towards the assessment of a coordinated health care system and makes up one of the basic means of audit for the rational distribution of human and economic resources. Moshiri et al. continue to say that in the last two decades efficiency measurement area of health services research has witnessed intensive exploration. This due to the extensive inefficiencies witnessed in the health sector across many countries.

According to Ditzel et al. (2006) efficient management of hospitals requires the responsible and effective use of funds, professional management, and competent governing structures.

Many studies on health sector efficiency and hospital efficiency have been conducted in the last two decade. Moelm and Beri (2016) carried out research in Cameroon health sector. They used financing data for two years from the national bureau of statistics data as their base for computing efficiency. They recommended that the line ministry put in more efforts geared towards ensuring a consistent increase in the overall efficiency by developing policies and procedures to control the wastage of valuable input resources and recruiting more qualified medical personnel. Kirigia and Asbu (2013) conducted technical and scale efficiency of public community hospitals in Eritrea. They employed funding, human resources, and facilities to assess the efficiency of hospitals. They pointed out that there was a growing realization among health policy-makers in the African Region of the need to utilize scarce health sector resources more efficiently, a good indication of which being the statement made by the 46 WHO the Member States of the African Region in 2006 stressing their commitment to increasing the efficiency of health interventions and improving the allocation and management of health sector resources. Jehu-Appiah et al. (2013) conducted a study on how ownership affects the efficiency of hospitals in public, private, faith-based and quasi-government and found out that majority of all categories of hospitals were operating far away from the efficient frontier. They concluded that it is wise for policy-makers to examine the least efficient hospitals to correct widespread inefficiency, with options considering hospitals distribution, improving efficiency and reducing duplication by closing or scaling down hospitals with efficiency scores below a certain threshold.

On analysis of the literature on efficiency, it was evident that efficiency estimation in health care systems has been done intensively in recent times. Various researchers have oriented studies on estimation of hospital efficiency to funding, human resources, commodities, and infrastructure. None has attempted to do anything on management. They only make mention of management of healthcare resources. This observation prompted this study with the objective of finding out the effect of management practices on hospital efficiency. We believe that management in all organizations hospitals included is key to converting all other available inputs into the desired outputs in terms of quality (how well or efficient) and quantity (volume) of health care services provided.

\section{Materials and Methods}

The study employed cross-sectional research design to collect the data used to estimate hospital efficiency levels. The data was collected from 75 hospital managers, three per hospital. These were hospital doctors in charge of the hospital or medical superintendent, nursing officer in charge and administration officer in charge. The managers' questionnaire tool was used to interview them after giving written consent. They were interviewed about their management styles and practices individually and scored between $0 \%$ and $100 \%$. The average score of the three managers was taken as the management score for the hospital. Twenty-five public hospitals in central Kenya were covered. This was taken as census because these were the only public hospitals in this area. They were chosen because they had similar environmental, social economic and health-seeking behavior. The interview of the managers was taken to find out if management had any correlation with hospital efficiency.

The hospital data was taken using a hospital data tool. This collected information from hospital records for both outpatients and inpatient services, inventories, ledgers and in post staff records for the 2011/2012 financial year. The data from hospital records were used as inputs and outputs of each hospital in estimating efficiency in twenty-five hospitals where each hospital stood as Decision Making Unit (DMU). Three inputs used in this study were the total number of beds, doctors, and nurses. The beds were considered to be basic fundamental infrastructure for all hospitals. The doctors and nurses were considered the two crucial human resources in a hospital to function considering hospitals are labor intensive. Secondly, efficiency depends on how well the available resources are utilized without wastage or misallocation and the two professional cadres (doctors \& nurses) are responsible for this, particularly for the hospitals.

On the side of outputs, the total outpatient visits and total admissions were chosen for the purpose of the estimation of efficiency of each hospital. The two outputs represented almost all services delivered in the 
hospitals. During data collection, the hospitals were given serial numbers and code numbers. In this study, the hospital codes numbers given were those given during service availability mapping.

The study employed a two-stage data analysis. The first stage employed data envelopment analysis (DEA) to compute efficiency scores (CRS, VRS \& SE) for the hospitals. While in the second stage it employed both ordinary least square (OLS) method, where the efficiency scores (CRS, VRS \& SE) obtained in the first stage were analyzed, that is, the efficiency scores were logged and regressed against managerial practices; and also in censored regression method (Tobit Model) where DEA efficiency scores (CRS, VRS \& SE) were regressed against determinants of efficiency using Tobin's method.

\subsection{Input Oriented Efficiency Determination of Efficiency: Data Envelopment Analysis (DEA)}

In this study, the researchers utilized physical available resource to hospital management to estimate hospital efficiency (number of beds, doctors, and nurses as hospital inputs, while total outpatient and inpatients as hospital outputs). The input-oriented efficiency determination employs resources at hand to produce as much output as possible (VRS). This is an input based measure of technical efficiency score (input orientation) of a health facility.

Using both hospital inputs and outputs the hospital efficiencies were estimated using DEA (Data Development Analysis) method which is a linear programming presented in the equations $(1,2,3)$ and Diagram explained below.

\subsubsection{Input Oriented Efficiency Measurement through Equation}

The DEA linear programming method that we used to estimate hospital efficiency levels can, in simplified form, be stated as follows:

$$
\operatorname{Max} H=\sum_{r=1}^{s} \operatorname{UrYrj}
$$

Subject to

$$
\begin{gathered}
\sum_{i=1}^{m} \operatorname{ViX} i j=1 \\
\sum_{r=1}^{s} \operatorname{UrYrj}=\sum_{i=1}^{m} \operatorname{ViXij}, j=1, \ldots, n ; U r, V i \geq 0
\end{gathered}
$$

Where,

$H=$ Monetary value of a well-defined level of health care service, e.g., the annual number of outpatients visits to a given hospital;

$Y_{r j}=$ Output $r$ for hospital $j$, e.g., the level of health care associated with a given number of outpatient visits to a given hospital;

$\mathrm{X}_{\mathrm{ij}}=$ Input $\mathrm{i}$ for hospitals $\mathrm{j}$, e.g., the number of doctors working in a given hospital;

$\mathrm{U}_{\mathrm{r}}=$ weight given to a unit of output $\mathrm{r}$, e.g., the monetary value of health care services associated with one outpatient visit to a hospital, i.e., the shadow value of such a visit;

$\mathrm{V}_{\mathrm{i}}=$ weight given to a unit of input i, e.g., the monetary value of a day's services rendered by a nurse at a hospital;

$\mathrm{n}=$ number of hospitals;

$\mathrm{m}=$ number of inputs;

$\mathrm{s}=$ number of outputs.

The first equation states that the value of the things that the hospital produces (whatever they are) is to be maximized. The second equation normalizes to unity the value of the inputs used to produce a given level of output. The last equation states that when $\mathrm{H}$ has been maximized, the value of a given output must be equal to the value of the inputs used to produce it. This must be the case because every unit of output requires resources to produce it. Therefore, its value cannot exceed the value of the resources used to produce it, as such a situation would imply that the value of output is based on something else other than the value of the inputs. Furthermore, the value of a unit of output cannot be smaller than the value of the inputs expended on its production because it is assumed that the inputs are not wasted or misallocated. The equation further states that the weights assigned to outputs and inputs must be strictly positive. This again must hold because things of value cannot have zero or negative weights, as that would contradict the fact that the things are useful. Together, the three equations imply that the efficiency score must be between zero and one, the values for complete inefficiency and complete efficiency, respectively. 
The above algorithm establishes a production frontier for efficient hospitals and measures how far down the inefficient hospitals are from the best practice frontier. The efficient hospitals lie on that frontier and are given an efficiency score of 1 . The inefficient hospitals are given a score that is less than 1 , the magnitude of the score depending on where the hospitals are relative to efficient ones. The efficient scores are classified according to the assumptions made in computing them, namely, constant returns to scale efficiency scores (CRS) and variable returns to scale scores (VRS) (Zere et al., 2000). Under the CRS assumption, the decision-making units (the hospitals in this case) are treated as if they are at their optimum sizes, whereas under the VRS assumption, the sizes of DMUs vary towards optimum sizes. Thus the CRS efficiency level cannot exceed the VRS level.

The ratio of CRS efficiency score to the VRS score is known as the scale efficiency score (SES). It is essentially the ratio of the output produced by a DMU when its size is not at the optimum level relative to the output produced when the size is optimum. Thus a scale efficiency score of 0.8 indicates a DMU is at $80 \%$ of the output that can be had when its size is optimum. A similar number for a CRS score says that $80 \%$ of output is being produced by an optimum-sized DMU so that the inefficiency level is only $20 \%$. Under the VRS assumption, the interpretation is that $80 \%$ of the maximum possible output is being produced by a DMU that is adjusting its scale towards the optimum size.

\subsubsection{Input Oriented Efficiency Measurement Graphically}

Farrell 1957 in Coelli (1996) exhibited by a simple example involving firms which used two inputs (X1 and X2) to produce a single output $(\mathrm{Y})$, under the assumption of constant returns to scale. The input-oriented implies an input reducing focus.

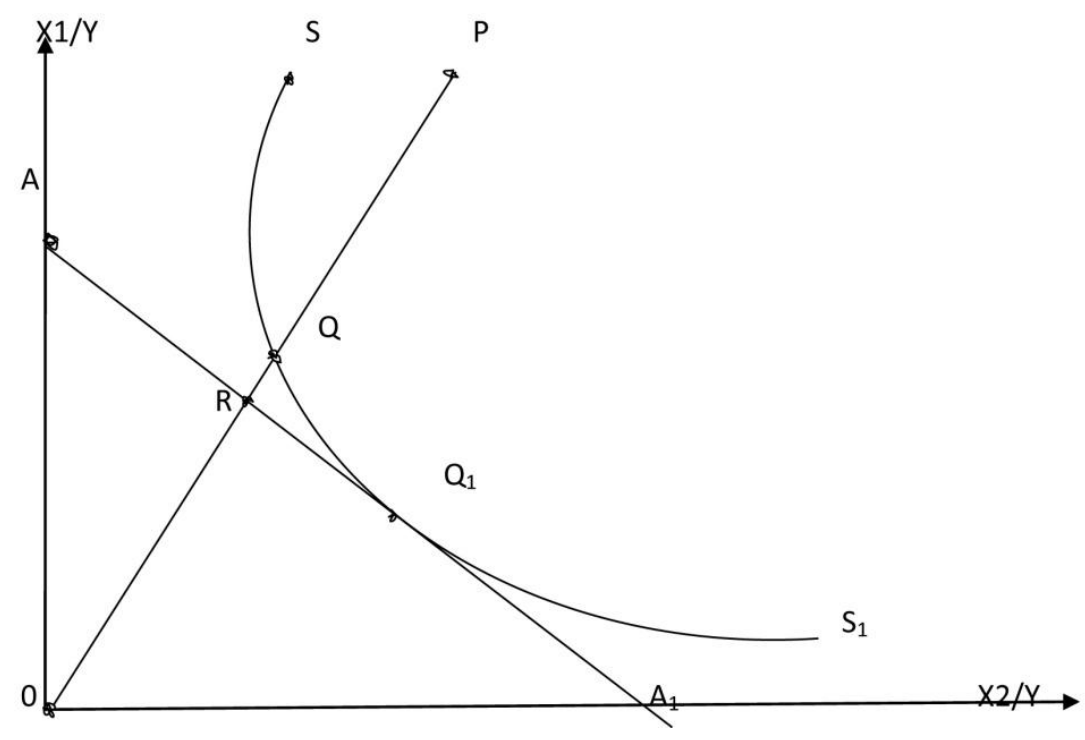

Figure 1. Farrel input-oriented efficiency measure

In Figure 1, the isoquant unit of a fully efficient firm is represented by SS1. This permits the measurement of technical efficiency. If a given firm uses quantities of inputs, defined by the point $\mathrm{P}$ to produce a unit of output, the technical inefficiency of that firm is represented by distance QP, which is the amount by which all input could be proportionally reduced without a reduction in output. This is usually expressed in percentage terms by the ratio $\mathrm{QP} / \mathrm{OP}$, which represents the percentage by which all inputs could be reduced. The technical efficiency (TE) of a firm is most commonly measured by the ratio:

$$
T E 1=O Q / O P
$$

This is equal to one minus $\mathrm{QP} / \mathrm{OP}$ i.e. (1-QP/OP). It will take a value between zero and one and hence provides an indicator of the degree of technical inefficiency of the firm. A value of one indicates the firm is fully technically efficient. For example, the point $\mathrm{Q}$ is technically efficient because it lies on the efficient isoquant.

If the input price ratio, represented by the line AA1 in Figure 1, is also known, a locative efficiency may be calculated. The locative efficiency (AE) of the firm operating at $\mathrm{P}$ is defined to be the ratio:

$$
A E 1=O R / O Q
$$


Since the distance, RQ represents the reduction in production cost that would occur if production were to occur at the allocative (and technically) efficient point Q1, instead of at the technically efficient, but allocative inefficient, point $\mathrm{Q}$. the total economic efficiency (EE) is defined to be the ratio:

$$
E E 1=O R / O P
$$

Where the distance RP can also be interpreted in terms of a cost reduction. Note that the product of technical and a locative efficiency provides the overall economic efficiency

$$
T E 1 * A E 1=(O Q / O P) *(O R / O Q)=(O R / O P)=E E 1(\text { Coelli, 1996) }
$$

Using the above formula and DEA method, the technical and scale efficiency for 25 hospitals were calculated.

\section{Results and Discussion}

\subsection{Descriptive Statistics}

Tables 1 and 2 present general characteristics of the sample hospitals. As can be seen from Table 1, the study area had a population of about 60,000 patients in 2011-12. On average, a hospital had 120 beds and the average bed occupancy was about 60 days. Another important statistic from the table is that 99 percent of the hospitals banked their facility improvement funds as stipulated by the Ministry of Health regulations. Moreover, $26 \%$ of this fund was earmarked for drug purchases, and the same proportion was used to meet the needs of hospital management.

Table 1. Basic sample statistics, inputs

\begin{tabular}{lccc}
\hline Variables & Observations & Mean & Std. Dev. \\
\hline Population of the catchment area (patients) & 17 & 59289.7 & 42592.03 \\
Number of beds & 25 & 121.3 & 113.6642 \\
Hospital occupied bed days & 25 & 60.1 & 31.05705 \\
Total staff & 25 & 156.7 & 137.7753 \\
Total number of doctors & 25 & 11.6 & 14.19178 \\
Total number of nurses & 25 & 75.2 & 74.95514 \\
Total Facility Improvement Fund (FIF) collected, Kshs & 25 & $2.84 \mathrm{E}+07$ & $3.19 \mathrm{E}+07$ \\
Proportion of FIF banked & 25 & 99.3 & 3.201333 \\
Percentage of FIF earmarked for drugs & 25 & 26.0 & 13.94226 \\
Percentage of FIF earmarked for management & 25 & 26.0 & 13.94226 \\
Total labor cost, Kshs & 25 & $1.63 \mathrm{E}+08$ & $1.82 \mathrm{E}+08$ \\
Capital expenditure, Kshs & 25 & $8.14 \mathrm{E}+07$ & $1.11 \mathrm{E}+07$ \\
\hline
\end{tabular}

Key: $1.63 \mathrm{E}+08=163,000,000.00 ; 8.14 \mathrm{E}+07=81,400,000.00$.

A few highlights from table 2 are in order. The table shows that on average the hospitals had about the same annual number of visits for outpatient and inpatient services, i.e., 71,000 and 67,000, respectively. The emergency wait time for outpatient care and caesarian sections were 9 minutes and 23 minutes, respectively. On average a hospital experienced 270 deaths per year, compared to annual deliveries of around 2340 and stillbirths of 34 .

Table 2. Basic sample statistics, outputs

\begin{tabular}{lccc}
\hline Variables & Observations & Mean & Std. Dev. \\
\hline Total outpatients & 25 & 71462.1 & 55574.1 \\
Total inpatients & 25 & 6736.2 & 7821.7 \\
Total surgical cases & 21 & 1012.5 & 1278.9 \\
Hospital occupancy, bed days & 24 & 33614.3 & 39350.0 \\
Total discharges & 25 & 5960.4 & 6449.6 \\
Total deaths & 25 & 270.5 & 301.9 \\
Emergency waiting time at outpatient departments, minutes & 23 & 9.1 & 10.3 \\
Emergency waiting time, caesarian sections, minutes & 18 & 23.1 & 12.3 \\
Total deliveries & 25 & 2341.7 & 2335.8 \\
Fresh still births, numbers & 25 & 33.8 & 56.4 \\
Total live births & 25 & 2284.8 & 2288.3 \\
Under one year deaths & 25 & 54.7 & 65.8 \\
Total under 5 admissions & 25 & 1486.5 & 2310.0 \\
\hline
\end{tabular}




\subsection{DEA Efficiency Scores}

Table 3 reports CRS, VRS and SE scores for all the 25 hospitals by size categories. As is evident from the table the small hospitals had the highest efficiency scores and the large hospitals had the lowest efficiency levels.

Table 3. Hospital efficiency levels

\begin{tabular}{|c|c|c|c|c|c|c|}
\hline \multicolumn{7}{|c|}{ Large hospitals: $200-400$ bed capacity } \\
\hline Code & Hospital & Bed capacity & CRS & VRS & SE & Comments \\
\hline 1 & Kiambu & 383 & 0.871 & 1.000 & 0.871 & DRS \\
\hline 2 & Thika & 299 & 0.569 & 1.000 & 0.569 & DRS \\
\hline 3 & Nyeri & 366 & 0.479 & 1.000 & 0.479 & DRS \\
\hline 4 & Kerugoya & 264 & 0.744 & 0.981 & 0.759 & DRS \\
\hline 5 & Muranga & 240 & 0.441 & 0.526 & 0.839 & DRS \\
\hline 6 & Karatina & 214 & 0.488 & 0.498 & 0.980 & IRS \\
\hline \multirow[t]{2}{*}{7} & Olkalaou & 200 & 0.398 & 0.423 & 0.940 & IRS \\
\hline & Average & & 0.57 & 0.78 & 0.7767 & \\
\hline \multicolumn{7}{|c|}{ Medium hospitals: $100-199$ bed capacity } \\
\hline Code & Hospital & Bed capacity & CRS & VRS & SE & \\
\hline 1 & Nyahururu & 154 & 1.000 & 1.000 & 1.000 & - \\
\hline 2 & Nanyuki & 129 & 0.606 & 1.000 & 0.606 & DRS \\
\hline 3 & Gatundu & 107 & 0.587 & 1.000 & 0.587 & DRS \\
\hline 4 & Mukurweini & 144 & 0.642 & 0.664 & 0.967 & IRS \\
\hline 5 & Maragua & 110 & 0.458 & 0.504 & 0.909 & IRS \\
\hline Average & & & 0.659 & 0.83 & 0.81 & \\
\hline \multicolumn{7}{|c|}{ Small hospitals: below 100-bed capacity } \\
\hline Code & Hospital & Bed capacity & CRS & VRS & SE & \\
\hline 1 & Ruiru & 22 & 1.000 & 1.000 & 1.000 & - \\
\hline 2 & Kianyaga & 23 & 1.000 & 1.000 & 1.000 & - \\
\hline 3 & Kangema & 7 & 1.000 & 1.000 & 1.000 & - \\
\hline 4 & Kimbimbi & 46 & 1.000 & 1.000 & 1.000 & - \\
\hline 5 & Othaya & 77 & 0.970 & 1.000 & 0.970 & IRS \\
\hline 6 & Engineer & 15 & 0.603 & 1.000 & 0.603 & IRS \\
\hline 7 & Nyathuna & 10 & 0.370 & 1.000 & 0.370 & IRS \\
\hline 8 & Kirwara & 16 & 0.839 & 0.877 & 0.957 & IRS \\
\hline 9 & Kihara & 66 & 0.681 & 0.858 & 0.794 & IRS \\
\hline 10 & Tigoni & 65 & 0.594 & 0.848 & 0.701 & DRS \\
\hline 11 & Igegania & 14 & 0.631 & 0.838 & 0.752 & IRS \\
\hline 12 & Muriranjas & 66 & 0.691 & 0.732 & 0.944 & IRS \\
\hline 13 & Mt Kenya & 21 & 0.227 & 0.676 & 0.335 & IRS \\
\hline Average & & & 0.74 & 0.91 & 0.80 & \\
\hline
\end{tabular}

Note. DRS = decreasing returns to scale; IRS = increasing returns to scale.

The efficiency scores in Table 3 show that $52 \%$ of hospitals were efficient, a number that compares favorably with a Ghanaian study that reported an efficiency rate of 53\% among the hospitals studied (Osei et al., 2005). Table 4 looks at factors that might be responsible for variation in efficiency scores (in Table 3) across hospitals. 


\subsection{Ordinary Least Square Regression}

Table 4. Management practices and hospital performance - dependent variable is log of efficiency score ( $t$-statistics in parentheses)

\begin{tabular}{|c|c|c|c|c|c|c|c|c|c|}
\hline Management practices & 1 & 2 & 3 & 4 & 5 & 6 & 7 & 8 & 9 \\
\hline $\begin{array}{l}\text { Work plan } \\
(\text { yes }=1)\end{array}$ & $\begin{array}{l}-0.005 \\
(-.96)\end{array}$ & & & & & & & & \\
\hline $\begin{array}{l}\text { Work plan implemented } \\
(\text { yes }=1)\end{array}$ & & $\begin{array}{l}-0.001 \\
(-1.1)\end{array}$ & & & & & & & \\
\hline $\begin{array}{l}\text { Staff Empowerment } \\
(\text { yes }=1)\end{array}$ & & & $\begin{array}{l}0.002 \\
(.37)\end{array}$ & & & & & & \\
\hline $\begin{array}{l}\text { Effective communication } \\
(\text { yes }=1)\end{array}$ & & & & $\begin{array}{l}-.006 \\
(-.80)\end{array}$ & & & & & \\
\hline $\begin{array}{l}\text { Delegation } \\
(\text { yes }=1)\end{array}$ & & & & & $\begin{array}{l}0.005 \\
(1.02)\end{array}$ & & & & \\
\hline $\begin{array}{l}\text { Daily supervision } \\
(\text { yes =1) }\end{array}$ & & & & & & $\begin{array}{l}0.014 \\
(3.14)\end{array}$ & & & \\
\hline $\begin{array}{l}\text { Motivation and inspiration } \\
\text { (yes=1) }\end{array}$ & & & & & & & $\begin{array}{l}-.004 \\
(-.78)\end{array}$ & & \\
\hline $\begin{array}{l}\text { Hospital residence } \\
(\text { yes = 1) }\end{array}$ & & & & & & & & $\begin{array}{l}-0.004 \\
(-.72)\end{array}$ & \\
\hline Constant & $\begin{array}{l}-0.005 \\
(1.16)\end{array}$ & $\begin{array}{l}0.004 \\
(1.13)\end{array}$ & $\begin{array}{l}0.009 \\
(-2.2)\end{array}$ & $\begin{array}{l}0.003 \\
(0.37)\end{array}$ & $\begin{array}{l}0.011 \\
(2.69)\end{array}$ & $\begin{array}{l}0.015 \\
(4.63)\end{array}$ & $\begin{array}{l}-0.006 \\
(-1.64)\end{array}$ & $\begin{array}{l}0.007 \\
(-2.31)\end{array}$ & $\begin{array}{l}0.003 \\
(-0.50)\end{array}$ \\
\hline$R$-squared & 0.017 & 0.012 & 0.009 & 0.008 & 0.010 & 0.122 & 0.0084 & 0000 & 0.004 \\
\hline Sample size & 73 & 75 & 75 & 74 & 75 & 74 & 74 & 75 & 75 \\
\hline
\end{tabular}

The results in Table 4 indicates that hospitals that supervise hospital activities daily, have a $1.4 \%$ higher efficiency scores than other hospitals that did not carry out daily supervision (supervision coeff $=.014, t=3.14$ ). Management improves efficiency through daily supervision practice which ensures inputs are not wasted or misallocated. No other management practice is statistically correlated with efficiency scores.

Table 5. Management practices and hospital performance controlling for hospital budget: dependent variable is $\log$ of hospital performance indicators index ( $t$-statistics in parentheses)

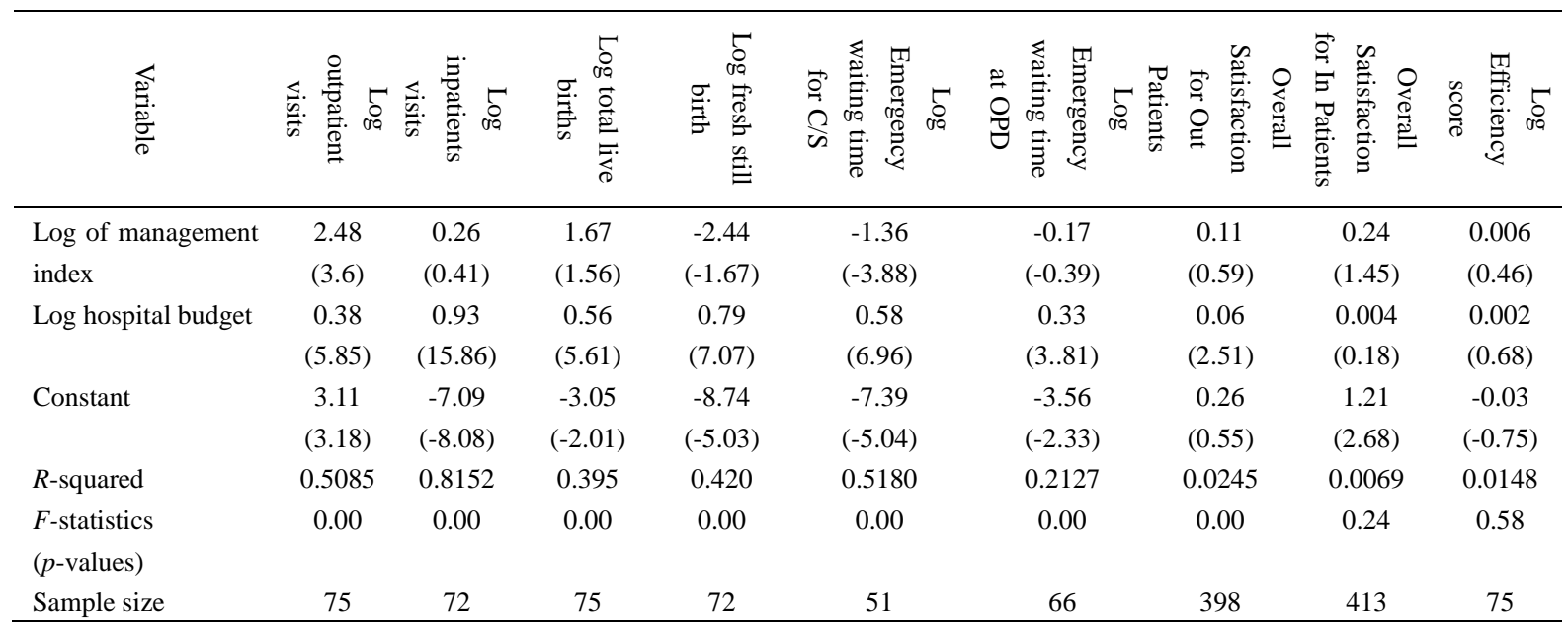

Table 5 shows that better management (a higher management index) is negatively associated with fresh stillbirths and with emergency wait time for Caesarian surgeries. In particular, a $1 \%$ increase in management index is associated with a $1.36 \%$ reduction in wait time $(\mathrm{t}=3.9)$. In addition, the regression coefficients shown in the table indicate that there is a positive relationship between management and the service volume (visits) and quality of health services (as evidenced by reductions in stillbirths and increases in live births) in the hospitals studied. 
It is also worth noting that although the hospital budget is positively correlated with patients' satisfaction with the services offered, the correlation is statistically insignificant. Interestingly, the management index is also positively but insignificantly correlated with hospital efficiency scores. This suggests that management does not improve service delivery via improvements in efficiency alone but also through increases in the inputs needed to deliver services. For example, a well-managed hospital (e.g., one that formulates and implements a work plan) would attract more resources from the government and other sources. Similarly, a hospital that empowers and motivates staff would, other things being constant increase the number of hours that the staff spends working, without necessarily increasing the yield from each hour worked. Effective supervision and communication would have similar effects. It is still of great value to emphasize that better management is positively correlated with hospital productivity (hospital efficiency score) only that this association is statistically insignificant.

\subsection{Tobit Regressions}

Since the covariates in Table 6 were not used in the DEA algorithm to compute the efficiency scores they can be used to the variation in the scores across hospitals. The main observation on the results in Table 4 is that covariates affect the three categories of efficiency scores differently. The male dummy is positively associated with the CRS and with scale efficiency scores possibly due to differences in managerial training between the two categories of staff. The coefficient on marriage dummy has coefficients that can be similarly interpreted.

A consistent finding in Table 6 is that the farther the hospital is from Nairobi, the lower is its efficiency score. In particular, a one percent increase in a hospital's distance from Nairobi reduces its VRS efficiency score by $1.1 \%$. A likely explanation for this finding is that the health ministry finds it difficult to supervise or support such a hospital effectively. The finding suggests that performance of hospitals located in remote areas can be improved by intensifying their external supervision. A notable finding in the table is the negative association between efficiency scores and manager's residence at a hospital. The manager's hospital residence can increase service demand excessively and compromise efficiency. The Pseudo R2s show the models in Table 6 fit the data quite well. In particular, about $76.3 \%$ of the variation in the VRS efficiency scores is explained by the variables shown in the model.

Table 6. Tobit regression results ( $t$ statistics in parentheses)

\begin{tabular}{cccc}
\hline & Dependent Variables & & \\
\hline Explanatory Variables & CRS Efficiency Scores & VRS Efficiency Scores & Scale Efficiency Scores \\
\hline Hospital size (1= large) & .185 & .354 & .253 \\
Dummy for sex (1=Male) & $(0.82)$ & $(0.96)$ & $(1.35)$ \\
& .361 & -.133 & .384 \\
Dummy for manager's residence & $(2.51)$ & $(-0.58)$ & $(3.14)$ \\
(1=hospital residence) & -.540 & -1.71 & .1078 \\
Dummy for marital status & $(-2.23)$ & $(-2.98)$ & $(0.54)$ \\
(1=married) & .419 & .319 & .436 \\
Log of Age & $(3.31)$ & $(1.62)$ & $(3.88)$ \\
& .574 & 5.10 & -2.152 \\
Log distance of the hospital & $(0.51)$ & $(3.08)$ & $(-2.32)$ \\
from manager's residence & -.162 & -.723 & .103 \\
Log manager's years of service & $(-1.50)$ & $(-2.82)$ & $(1.13)$ \\
& -1.31 & -2.63 & -.459 \\
Log of distance of the hospital & $(-2.99)$ & $(-2.63)$ & $(-1.27)$ \\
from Nairobi & -.268 & -1.102 & .182 \\
Log of average length of stay at & $(-1.47)$ & $(-3.00)$ & $(1.19)$ \\
the hospital & -.563 & -.873 & -.377 \\
Constant term & $(-2.7)$ & $(-2.37)$ & $(-2.12)$ \\
LR Chi-square statistic & 1.58 & -1.22 & 3.83
\end{tabular}




\section{Conclusion}

The objective of this study was to investigate the effect of management practices on hospital efficiency. The overall observation was that small hospitals had higher efficiency than medium and large hospitals. The results from OLS regression revealed that a majority of management practices identified in this study improved hospital outcomes or productivity positively and therefore pointed to improved efficiency of the hospitals. However, only daily supervision was directly correlated with improving hospital efficiency.

The researchers went further and did a Tobit regression to analyze manager and environmental related factors that contributed to different hospital efficiencies yet they had proportionate inputs (finances, human resources, equipment and medical supplies) and applied similar management practices. From the results, it was concluded that married managers were more efficient than unmarried ones. Contrary to the results, resident managers perform better as shown by reduction in emergency wait time for caesarian surgery and fresh stillbirth. The further distance of manager's residence to the hospital reduced hospital efficiency. The results also showed that the more years of service the manager had the more inefficient they were, this could be attributed to preoccupation with retirement and also private practice especially for doctors. It was also concluded that the longer the distance of hospital from Nairobi the more inefficient the hospitals were. These findings suggest that efficiency of hospitals can be improved by strengthening mechanisms for their internal supervision and by intensifying their external supervision by national health authorities. The average length of stay of the patient in hospitals was associated with poor efficiency scores of VRS, CRS and Scale efficiencies as well as clinical management emanating from poor general management.

This research concludes that individual manager's attributes, some specific management practices (empowerment, delegation, daily supervision and residence of managers in hospitals) plus hospital environmental factors directly or indirectly determined the hospital's efficiency. The researchers recommend that the management practices identified here to be applied in hospitals throughout the country. Also, the personal attributes and environmental factor be used to identify potential managers. This study concludes that better management improves hospital efficiency and hospital performance in terms quality and quantity (volume) of services rendered. This research concludes that management impact on all types of health resources. The authors recommend health policy-makers worldwide to invest in appropriate health and facility management if they were to eliminate resource wastage and misallocation. Finally, there is need to conduct follow up studies on hospital management and hospital efficiency.

\section{Authors' Contributions}

FKM, JM, GM, UK and BE were equally involved in the literature review, data analysis, interpretation of the results, and drafting of the manuscript. Five of authors read and approved the final manuscript.

\section{Acknowledgments}

The authors acknowledge the assistance provided by the hospital managers, health workers, patients and communities in central Kenya from whom they learnt so much. This paper is extracted from the thesis submitted by the first author in partial fulfillment of the requirements for the degree of Doctor of Philosophy, in public health, Institute of Tropical and Infectious Diseases- University of Nairobi.

\section{Competing Interests}

The authors declare that they have no competing interests.

\section{References}

Ali, M., Debela, M., \& Bamud, T. (2017). Technical efficiency of selected hospitals in Eastern Ethiopia. Health Economics Review, 7(24), 1-13. https://doi.org/10.1186/s13561-017-0161-7

Charnes, A., Cooper, W. W., \& Rhodes, E. (1978). Measuring the efficiency of decision-making units. European Journal of Operations Research, 2(6), 429-444. https://doi.org/10.1016/0377-2217(78)90138-8

Coelli, T. J. (1996). A guide to DEAP Version 2.1: A Data Envelop Analysis (Computer) Program. Center for Efficiency and Productivity Analysis (CEPA) Working Papers, No. 8/96, University of New England, Armidale, Australia. Retrieved from http://www.une.edu.au/econometrics/cepawp.html

Ditzel, E., Štrach, P., \& Pirozek, P. (2006). An inquiry into good hospital governance: A New Zealand-Czech comparison. Health Research Policy and Systems 2006, 4(2). https://doi.org/10.1186/1478-4505-4-2

Farrell, M. J. (1957). The measurement of productive efficiency. J. R. Stat Soc., 120, 253-290. https://doi.org/10.2307/2343100 
Jehu-Appiah et al. (2014). Ownership and technical efficiency of hospitals: Evidence from Ghana using data envelopment analysis. Cost Effectiveness and Resource Allocation, 12(9). https://doi.org/10.1186/1478-7547-12-9

Kirigia, J. M., Fox-Rushby, J., \& Mills, A. (1998). A cost analysis of Kilifi and Malindi District hospitals in Kenya. Afr. J. Health Sci., 5, 79-84.

Mills, A., Kapalamula, J., \& Chisimbi, S. (1991). The cost of the district hospital: A case study in Malawi. Bull World Health Organ, 71, 329-339.

Molem, M. C., \& Biongnyuy, B. P. (2016). Assessing the Technical Efficiency of Public Hospitals in Cameroon: An Application of Data Envelopment Analysis (DEA). International Journal of Humanities Social Sciences and Education, 3(3), 32-40. Retrieved from http://www.arcjournals.org

Moshiri, H., Aljunid, W. N., Amin, R. M., Dahlui, M., \& Ibrahim, W. N. (2011). Measuring technical efficiency of teaching hospitals in Malaysia. International Journal of Business Management, 6(4), 207-213. https://doi.org/10.5539/ijbm.v6n4p207

Nazgul, M. (2011). Efficiency Analysis of the Health Centres in Karaganda oblast. Kazakhstan: Data envelopment and Malmquist index analysis; UMEA, University.

Osei, D., d'Almeida, S., George, M. O., Kirigia, J. M., Mensah, A. O., \& Kainyu, L. H. (2005). Technical Efficiency of Public District Hospitals and Health Centers in Ghana: A pilot study. Cost Effectiveness and Resource Allocation, 3(1), 9. https://doi.org/10.1186/1478-7547-3-9

Zere, E. A., Addison, T., \& McIntyre, D. (2000). Hospital efficiency in sub-Saharan Africa: Evidence from South Africa. South African Journal of Economics, 69(2), 336-358. https://doi.org/10.1111/j.1813-6982.2001.tb00016.x

\section{Copyrights}

Copyright for this article is retained by the author(s), with first publication rights granted to the journal.

This is an open-access article distributed under the terms and conditions of the Creative Commons Attribution license (http://creativecommons.org/licenses/by/4.0/). 